\title{
Next-Generation Allergic Rhinitis Care in Singapore: 2019 ARIA Care Pathways
}

Xuandao Liu, ${ }^{1}$ MBBS (S'pore), MRCS (Edin), De Yun Wang, ${ }^{2}$ MD, PhD, Tze Choong Charn, ${ }^{1}$ MBBS (S'pore), MRCS (Edin), MMed (ORL),

Leslie Timothy Koh, ${ }^{3}$ MBBS, MRCS (Edin), MMed (ORL), Neville WY Teo, ${ }^{4}$ MBBS (S'pore), MRCS (Glas), MMed (ORL),

Yew Kwang Ong, ${ }^{5}$ MBBCh (Hons) (U.Dubl), MRCS(Edin), MMed(ORL), Mark KT Thong, ${ }^{5}$ MBBS (S'pore), MRCS (Edin), MMed (ORL),

Claus Bachert, ${ }^{6}$, Oliver Pfaar, ${ }^{7}$, Holger J Schünemann, ${ }^{8}$, Anna Bedbrook, ${ }^{9}{ }_{B S c}$,

Wienczyslawa $\underline{\text { Czarlewski, }}{ }^{10}{ }_{M D}$, Jean Bousquet,,${ }^{9,11,12,13,14}$ MD

\begin{abstract}
Allergic rhinitis (AR) is prevalent in Singapore, with a significant disease burden. Afflicting up to $13 \%$ of the population, AR impairs quality of life, leads to reduced work productivity and is an independent risk factor for asthma. In the last 2 decades, local studies have identified patient and physician behaviours leading to suboptimal control of the disease. Yet, there is an overall lack of attention to address this important health issue. Allergic Rhinitis and its Impact on Asthma (ARIA) is a European organisation aimed at implementing evidence-based management for AR worldwide. Recent focus in Europe has been directed towards empowering patients for self-management, exploring the complementary role of mobile health, and establishing healthcare system-based integrated care pathways. Consolidation of these ongoing efforts has led to the release of the 2019 ARIA care pathways. This review summarises the ARIA update with particular emphasis on the current status of adult AR in Singapore. In addition, we identify unmet needs and future opportunities for research and clinical care of AR in the local context.
\end{abstract}

Ann Acad Med Singap 2020;49:885-96

Keywords: Allergen immunotherapy, Allergic Rhinitis and its Impact on Asthma, clinical guideline

\section{Introduction}

Allergic rhinitis (AR) is a common global health issue estimated to affect up to $25 \%$ of children and over $40 \%$ of adults. ${ }^{1}$ The prevalence of the disease in Asia is rising over the past decade, possibly owing to improved hygiene, changing environment and genetic susceptibilities. ${ }^{2}$ Poorly controlled AR impairs quality of life, leads to reduced work productivity and is an independent risk factor for asthma. ${ }^{2-5} \mathrm{~A}$ recent study estimated the indirect costs of inadequately treated allergic diseases in Asia to be more than US $\$ 100$ billion per year. ${ }^{6}$

Allergic Rhinitis and its Impact on Asthma (ARIA) is a European non-governmental organisation with a mission to educate and implement evidence-based management

\footnotetext{
${ }^{1}$ Department of Otolaryngology, Head and Neck Surgery, Sengkang General Hospital, Singapore

${ }^{2}$ Department of Otolaryngology, National University of Singapore, Singapore

${ }^{3}$ Department of Otorhinolaryngology, Head and Neck Surgery, Changi General Hospital, Singapore

${ }^{4}$ Department of Otorhinolaryngology, Head and Neck Surgery, Singapore General Hospital, Singapore

${ }^{5}$ Department of Otolaryngology, Head and Neck Surgery (ENT), National University Hospital, Singapore

${ }^{6}$ Upper Airways Research Laboratory, Department of Oto-Rhino-Laryngology, Ghent University Hospital, Belgium

${ }^{7}$ Department of Otorhinolaryngology, Head and Neck Surgery, Section of Rhinology and Allergy, University Hospital Marburg, Germany

${ }^{8}$ Department of Health Research Methods, Evidence and Impact, Division of Immunology and Allergy, McMaster University, Canada

${ }^{9}$ MACVIA-France, Montpellier, France

${ }^{10}$ Medical Consulting Czarlewski, Levallois, France

${ }^{11}$ INSERM U 1168, VIMA: Ageing and Chronic Diseases Epidemiological and Public Health Approaches, Villejuif, Université Versailles St-Quentin-en-Yvelines, Montigny le Bretonneux, France

${ }^{12}$ European Forum for Research and Education, Brussels, Belgium

${ }^{13}$ Charité, Universitätsmedizin Berlin, Humboldt-Universität zu Berlin, Germany

${ }^{14}$ Berlin Institute of Health, Comprehensive Allergy Center, Department of Dermatology and Allergy, Germany

Address for Correspondence: Prof De Yun Wang, Department of Otolaryngology, National University Health System, National University of Singapore, 1E Kent Ridge Road, NUHS Tower Block, Singapore 119228.

Email: entwdy@nus.edu.sg
} 
for AR and asthma worldwide. ${ }^{7}$ In Singapore, the recommendations of the ARIA 2008 document were incorporated into the Singapore Ministry of Health (MOH) rhinosinusitis and AR clinical practice guidelines $2010{ }^{8}$ However, the ministry considers guidelines to be withdrawn 5 years after publication. ${ }^{9}$

It is therefore timely to review the developments in AR management in Singapore. The information presented in this article pertains mainly to adult AR. First, we examine the status of AR in Singapore along with new therapeutic options. Next, we present key updates to ARIA and outcomes of recent research activities by our European counterparts. Finally, we consider unmet needs and future directions for AR management in Singapore.

\section{Situation in Singapore}

\section{Status of AR}

The overall prevalence of AR in Singapore is estimated to be $5.5-13 \%{ }^{10,11}$ It is more prevalent among the younger age groups, with a peak prevalence of up to $44 \%$ between the ages of 10 and 19 years. ${ }^{10}$ With an equatorial climate that is warm and humid year-round, persistent AR is the predominant pattern of disease. The allergic response is dominated by a single allergen class, with more than $80 \%$ of the local population sensitised to house dust mites (HDM). ${ }^{12}$ Polleninduced, seasonal AR does not affect Singapore, although smoke haze pollution from uncontrolled forest fires of surrounding countries during certain months has been found to increase hospital attendances for asthma and rhinitis. ${ }^{13}$

As a relatively affluent nation with a doctor-topopulation ratio of $1: 410,{ }^{14}$ along with efficient healthcare and transport systems with strategically planned facilities, quality healthcare in Singapore both accessible and affordable. Thus, barriers to adequate AR care are low. When general practitioners (GPs) in primary care are unable to adequately manage difficult cases of AR, referrals to otolaryngology specialist outpatient clinics at the 9 restructured (government-linked) hospitals are typically available within 60 days. For those opting for private healthcare, they are typically able to consult a private specialist within 2 weeks.

Yet, the control of disease is often suboptimal, owing to the patients' poor compliance with medications, their poor understanding of disease, and ineffective or inappropriate prescription by primary care physicians. ${ }^{10,15,16}$ Patients prescribed intranasal steroids (INSs) are frequently non-compliant with treatment. ${ }^{16}$ The noncompliance is largely due to inadequate patient education. Primary care physicians, who see up to $70 \%$ of AR patients, are often limited by the high volume of patients and financial constraints (especially for private practitioners). ${ }^{15}$ As a result, many do not have the time to counsel patients adequately. There is also a preference to prescribe quick-relief medications such as decongestants, which provide short-term symptom relief but no durable long-term control, with potential side effects. Among patients and some primary care physicians, there is a perception that steroids are dangerous; hence, INSs are only prescribed as a short course or used as needed. INS prescriptions may also be under-dosed by primary care physicians, resulting in suboptimal control of disease. Enhancements in information access in a digitally connected world, changes in attitudes towards personal health, and the expanding primary healthcare sector in Singapore may have significantly impacted AR care.

\section{New developments and therapeutic options available}

A comprehensive review of evidence-based management, including pharmacological options in the treatment of AR in Singapore, has been published by Lim and Leong in $2010 .{ }^{17}$ A summary of the common medications used locally for AR is presented in Table 1 .

In this section, we discuss several landmark regulatory changes in the last few years that may change prescription practices.

\section{Cost of medications}

The government provides substantial subsidies to Singaporeans at polyclinics (government-linked primary care facilities) and subsidised specialist outpatient clinics in public hospitals for medicinal items in the $\mathrm{MOH}$ standard drug list. ${ }^{19}$ This list is under yearly review by an appointed body of medical professionals, that is the Drug Advisory Committee.

Recent additions to the list included 2 INSs, mometasone furoate and triamcinolone acetonide. The new additions lower the retail price from over $\mathrm{S} \$ 20$ to approximately $\mathrm{S} \$ 10$ per bottle (140 metered actuations). The reduction in cost may improve access and compliance for patients on this treatment and may influence physicians' prescriptive behaviour. ${ }^{20}$ Fluticasone furoate remains unsubsidised.

Loratadine remains the only newer generation, nonsedating antihistamine on the subsidised drug list. Montelukast, a leukotriene-receptor antagonist that is useful in patients with both AR and asthma, is not subsidised.

\section{New and yet-to-be approved medications}

The Health Sciences Authority (HSA) regulates therapeutic products in Singapore under the Health Products 
Table 1. Common pharmaceutical options for treatment of allergic rhinitis in Singapore

\begin{tabular}{|c|c|c|c|c|}
\hline Class & Examples & Mechanism of action & Benefits and advantages & Potential risks and disadvantages \\
\hline $\begin{array}{l}\text { Oral } \\
\text { antihistamines }\end{array}$ & 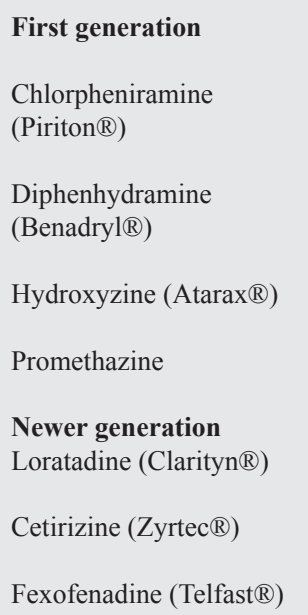 & $\begin{array}{l}\text { Blocks the action of } \\
\text { histamine at } \mathrm{H}_{1} \\
\text { receptor sites }\end{array}$ & $\begin{array}{l}\text { Reduces allergic symptoms such as } \\
\text { sneezing, itch and rhinorrhoea } \\
\text { Easy administration via oral tablets } \\
\text { Easily obtained; may be purchased } \\
\text { over the counter }\end{array}$ & $\begin{array}{l}\text { First generation antihistamines } \\
\text { cause sedation and anticholinergic } \\
\text { effects (e.g. urinary retention) }\end{array}$ \\
\hline Decongestants & 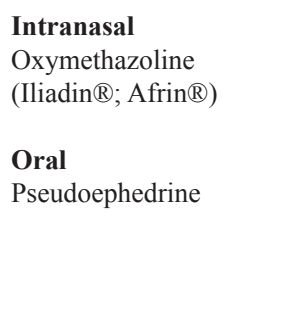 & $\begin{array}{l}\text { Activates alpha- } \\
\text { adrenergic receptors in } \\
\text { nasal mucosa, leading } \\
\text { to vasoconstriction }\end{array}$ & $\begin{array}{l}\text { Short-term relief of nasal } \\
\text { obstruction } \\
\text { Useful adjunct in initial therapy in } \\
\text { severely blocked noses } \\
\text { Pseudoephedrine often found in } \\
\text { combination with antihistamines } \\
\text { for convenience }\end{array}$ & $\begin{array}{l}\text { Prolonged use can lead to } \\
\text { rebound congestion (rhinitis } \\
\text { medicamentosa) } \\
\text { Oral decongestants have a } \\
\text { weaker effect on decongestion, } \\
\text { and may raise blood pressure }\end{array}$ \\
\hline $\begin{array}{l}\text { Intranasal } \\
\text { glucocorticoids }\end{array}$ & 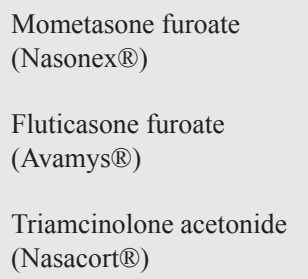 & $\begin{array}{l}\text { Binds to } \\
\text { intracellular } \\
\text { glucocorticoid } \\
\text { receptors, leading } \\
\text { to down-regulatory } \\
\text { effect on inflammatory } \\
\text { cells and cytokines }\end{array}$ & $\begin{array}{l}\text { Effective in ameliorating all AR } \\
\text { symptoms } \\
\text { Suitable for long-term use } \\
\text { Minimal to no systemic absorption }\end{array}$ & $\begin{array}{l}\text { Slower onset of action (maximum } \\
\text { efficacy may not be apparent up to } \\
2 \text { weeks } \\
\text { Local side effects e.g. dryness, } \\
\text { crusting, epistaxis }\end{array}$ \\
\hline $\begin{array}{l}\text { Leukotriene } \\
\text { receptor } \\
\text { antagonists }\end{array}$ & Montelukast (Singulair ${ }^{\circledR}$ ) & $\begin{array}{l}\text { Blocks action of } \\
\text { leukotrienes released } \\
\text { by mast cells }\end{array}$ & $\begin{array}{l}\text { Similar therapeutic profile to } \\
\text { antihistamines } \\
\text { More beneficial to patients } \\
\text { with comorbid asthma and aspirin- } \\
\text { exacerbated respiratory disease }\end{array}$ & $\begin{array}{l}\text { Generally well-tolerated, mild } \\
\text { side effects e.g. headache, } \\
\text { gastrointestinal symptoms }\end{array}$ \\
\hline
\end{tabular}

Source:

17. Lim MY, Leong JL. Allergic rhinitis: evidence-based practice. Singapore Med J 2010;51:542-50.

18. Bousquet J, Khaltaev N, Cruz AA, et al. Allergic Rhinitis and its Impact on Asthma (ARIA) 2008 update (in collaboration with the World Health Organization, GA²LEN and AllerGen). Allergy 2008;63 (Suppl 86):8-160.

Act. ${ }^{21}$ All therapeutic products will require registration with HSA before they can be supplied to patients in Singapore.

The azelastine hydrochloride and fluticasone propionate combination nasal spray is a relatively new addition to the market that was approved in June 2017. This combination intranasal antihistamine and steroid spray has greater efficacy and quicker onset of action than monotherapy.

Some medications have not been approved by or registered with HSA but are available in Singapore via an exemption scheme called Special Access Route. ${ }^{22}$ Two notable examples are the ipratropium bromide nasal spray and the Dermatophagoides pteronyssinus/ Dermatophagoides farinae (house dust mites) extract tablets. Ipratropium is an antimuscarinic (anticholinergic) that is effective in controlling rhinorrhoea, especially in cases of vasomotor rhinitis or chronic rhinitis where rhinorrhoea is the predominant symptom. ${ }^{18}$ The dust mite extract is used in sublingual immunotherapy for dust mite AR. Both products are available in Singapore, but the supply is limited to hospital pharmacies 
that have applied for the exemption scheme from HSA. In the authors' experience, physician take-up and prescription patterns are inconsistent, and the availability and awareness of these drugs in primary care are likely low.

\section{Next-Generation Guidelines}

\section{History of ARIA}

The first ARIA document was published in 2001. It was a state-of-the art review to provide healthcare professionals knowledge updates on the basic science, diagnosis and treatment of AR, and to propose an evidence-based, step-wise approach to the management of the disease. ${ }^{7}$ The ARIA 2008 update $^{18}$ introduced a pocket guide containing multiple diagnostic and management algorithms that remain largely relevant today (Fig. 1). This was also the version of ARIA guidelines that the $\mathrm{MOH}$ clinical practice guidelines 2010 adopted.

While primarily established to create evidence-based guidelines for AR, ARIA has dramatically evolved and expanded the scope of its activities in response to unmet needs in AR. From 2010, ARIA adopted the GRADE (Grading of Recommendations, Assessment, Development and Evaluation) approach, which considers relevant values, preferences, clinical circumstances and clinical expertise in addition to the up-to-date evidence to formulate recommendations. In the last few years, there has been a shift of focus towards real-world evidence, mobile smart device healthcare applications (mobile health) and integrated care pathways for AR. ${ }^{23}$

While randomised controlled trials are recognised as the gold standard for evidence of efficacy of interventions, many shortcomings limit its applicability to real-life situations. ${ }^{24}$ Homogeneous patient populations studied in ideal environments, involving free medications, high frequency follow-up and compliance monitoring, hardly reflect the realities of day-to-day clinical practice. There is therefore a need for the study of a complementary data source in real-world evidence, referring to information on healthcare derived from multiple sources outside typical clinical research settings, including electronic health records and data gathered through personal devices and health applications. ${ }^{25}$ While randomised controlled trials remain an important tool in the assessment of efficacy, real-world evidence plays an increasingly important role in achieving better clinical patient care.

Mobile health (mHealth) is the practice of medicine supported by mobile devices such as mobile phones, tablet computers and wearable devices. ARIA employs these emerging technologies to advance personalised and predictive medicine, and help establish integrated care pathways. Integrated care pathways are structured multidisciplinary care plans detailing key steps of patient care that promote the translation of guideline recommendations into local protocols and their application to clinical practice. The Mobile Airways Sentinel Network (MASK) is the mHealth arm of ARIA that has developed a free mobile application called MASK-air, which allows patients and the healthcare professional to co-manage allergic diseases. ${ }^{26}$ This app works as an allergy diary, allowing patients to log their daily measurements of general, nasal, ocular and asthma symptoms using a digitalised visual analogue scale (VAS), as well as their daily medication usage. Data collected from the mobile application may be used in conjunction with a clinical decision support system algorithm (Fig. 2A and 2B), which assists healthcare professionals to titrate pharmacotherapy based on disease severity. Some of the key findings of the MASK study are shown in Fig. 3. ${ }^{26,27}$ MASK is now a good practice of the European Commission's Directorate-General for Health and Food Safety ${ }^{28}$ and is evolving towards nextgeneration care pathways. ${ }^{29}$

Potential biases of mobile health studies include sampling bias, outcome misclassification and, due to patient privacy or confidentiality problems, availability of patient characteristics information. Mobile health users from the MASK study were not representative of all patients with rhinitis. Cross-sectional analysis of days in MASK was preferred ${ }^{26}$ because there was no clear pattern of treatment and a longitudinal study was not feasible as users mainly used the app intermittently. Most users were likely to have rhinitis (allergic or non-allergic) even though there was no confirmed diagnosis by a physician. ${ }^{26}$ Nonetheless, mobile technology is rapidly becoming an important tool to better understand and manage AR, and adds novel information that is not available with other methods. ${ }^{26}$

In Singapore, mHealth is still in its infancy. While the use of mobile apps and devices to track activity and calorie balance is commonplace, the application of $\mathrm{mHealth}$ for direct medical management is rare. As of this writing, there have been no large-scale efforts to promote the use of mHealth for AR management. In a local study evaluating the public attitudes towards mHealth, Hossain et al $^{30}$ found that while there were positive attitudes towards it, usage of mHealth was low. Lack of willingness to pay for the service and socio-economic factors (e.g. affluence) were identified as potential barriers to its widespread adoption.

\section{Next-generation ARIA guidelines}

A meeting held in Paris on 3 December 2018 was 


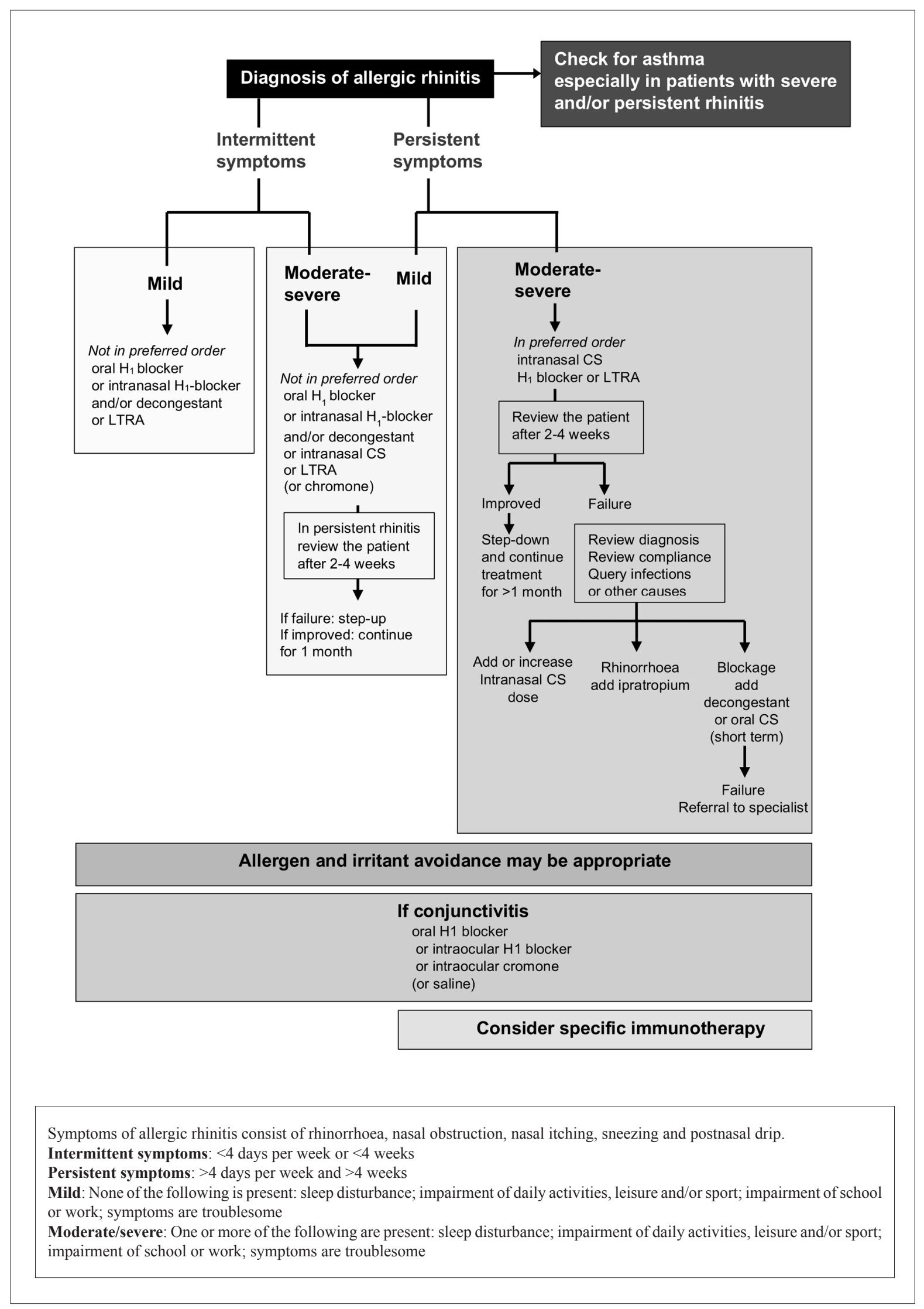

Fig. 1. Recommendations of the ARIA 2008 update. CS: corticosteroid; LTRA: leukotriene receptor antagonist. 
Assessment of control in untreated symptomatic patient

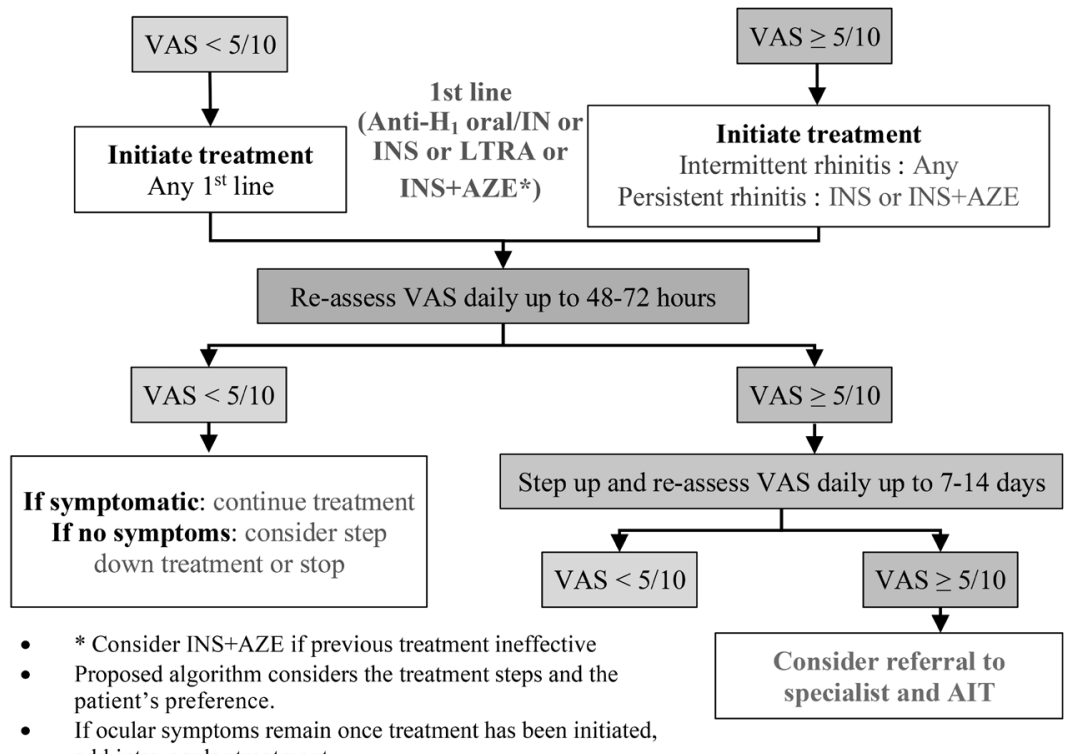

- If ocular symptoms remain once treatment has been initiated,

add intra-ocular treatment.

Fig. 2A. Step-up algorithm in untreated patients using visual analogue scale (adolescents and adults). Reproduced with permission from Bousquet J, Schunemann HJ, Hellings PW, et al. MACVIAclinical decision algorithm in adolescents and adults with allergic rhinitis. J Allergy Clin Immunol 2016;138:367-74 e2. AIT: allergen immunotherapy; AZE: azelastine; IN: intranasal; INS: intranasal steroid; LTRA: leukotriene receptor antagonist; VAS: visual analogue scale

\section{Assessment of control in treated symptomatic patient}

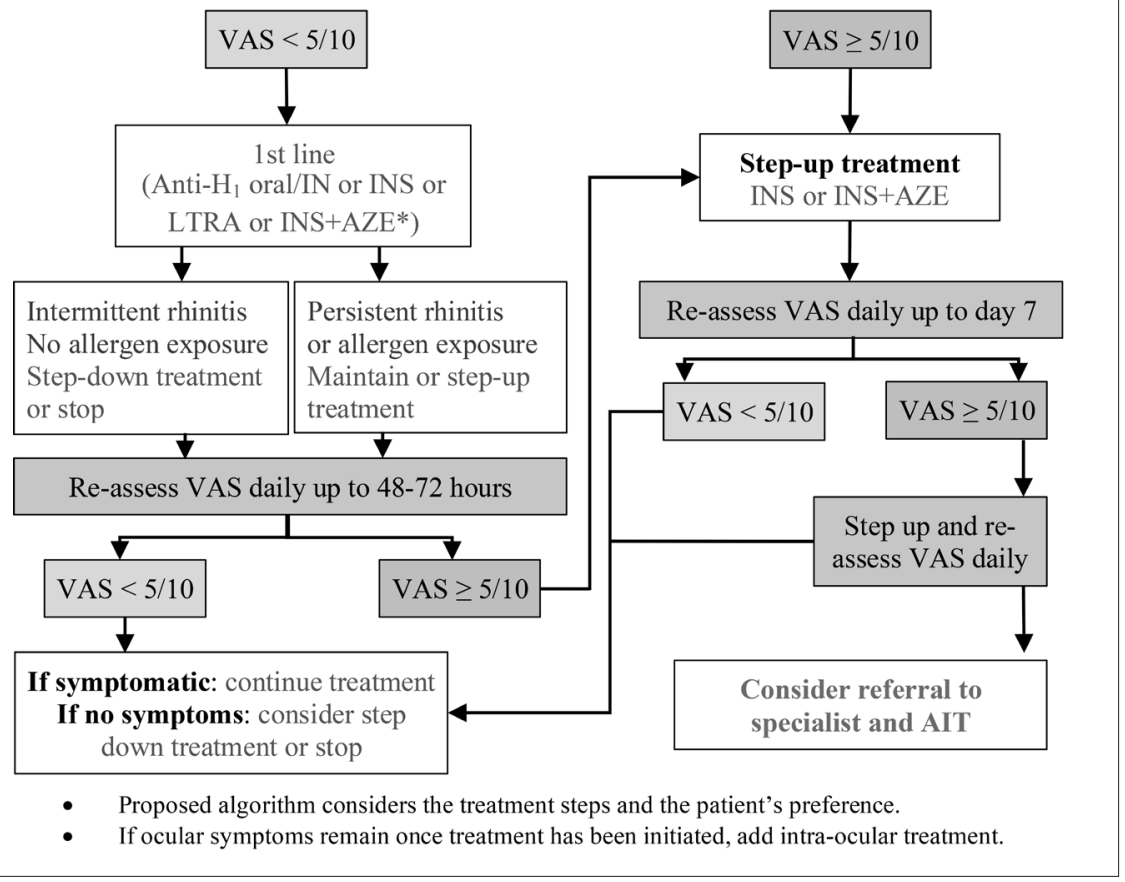

Fig. 2B. Step-up algorithm in treated patients using visual analogue scale (adolescents and adults). Reproduced with permission from Bousquet J, Schunemann HJ, Hellings PW, et al. MACVIAclinical decision algorithm in adolescents and adults with allergic rhinitis. J Allergy Clin Immunol 2016;138:367-74 e2. AIT: allergen immunotherapy; AZE: azelastine; IN: intranasal; INS: intranasal steroid; LTRA: leukotriene receptor antagonist, VAS: visual analogue scale 
- Patients did not follow guidelines and often selfmedicate.

- Adherence to treatment was poor.

- Patients treated themselves as they need, depending on the control of the disease, and increased their treatment when they were unwell. However, co-medication did not improve the control.

- Combination of intranasal azelastine plus fluticasone is superior to intranasal steroids, which are superior to oral $\mathrm{H}_{1}$-antihistamines.

Fig. 3. Results of real-world data for the treatment of allergic rhinitis

organised by MASK and Impact of Air Pollution on Asthma and Rhinitis (POLLAR) of the European Institute of Innovation and Technology Health (EIT Health), ${ }^{31}$ in collaboration with professional and patient organisations in the field of allergy and airway diseases..$^{32}$ During this meeting, next-generation guidelines for the pharmacological treatment of AR were developed and refined with real-world evidence provided by mobile technology and chamber studies. ${ }^{32}$ The outcome was the MASK algorithm to propose step-up or step-down AR treatment (Fig. 2A and 2B). ${ }^{33}$ Notable changes include the adoption of VAS to simplify severity assessment and the shift away from physician-directed pharmacotherapy towards self-titration and self-management by patients based on severity and frequency of symptoms.

In using VAS, the physician asks the patient to grade the severity of his or her AR symptoms (Fig. 4). The VAS has been shown to correlate well with the ARIA classification of symptom severity, as well as other symptom and quality of life measuring instruments. ${ }^{34}$ In particular, a VAS $\geq 5 / 10$ indicates moderate to severe AR. It is also easy to use and time-saving.

The proposed approach confirms the validity of most ARIA recommendations for AR. Overall, the important points in AR guidelines remain relevant (Fig. 5)..$^{1,33,35,36}$

\section{ARIA care pathways for allergen immunotherapy}

Allergen immunotherapy (AIT) is a proven therapeutic option for the treatment of AR, asthma, or both, by sublingual immunotherapy (SLIT) or subcutaneous immunotherapy (SCIT). ${ }^{35,40,41}$ In Singapore, AIT is more expensive than other medical treatments for AR or asthma and should therefore be considered in patients within a stratified medicine approach. ${ }^{18}$
Overall, how much are your allergic rhinitis symptoms bothering you in the last few weeks or months?

Not at all $\quad$ Extremely

bothersome bothered

Fig. 4. Visual analogue scale (VAS) in assessing allergic rhinitis control. The patient is presented a scale in the form of a single horizontal line on a piece of paper and is asked the following question: "Overall, how much are your allergic rhinitis symptoms bothering you in the last few weeks or months?" In response, the patient makes a mark on the scale (usually $10 \mathrm{~cm}$ ), which ranges from 'not at all bothersome' to 'extremely bothersome'. The mark on the line can then be measured and translated to a number on a 10 -point scale ( 0 to 10 ). This process should be repeated over follow-ups to monitor response to treatment. Physicians may also use the VAS for specific nasal, ocular, asthma symptoms, or degree of work impairment.

\section{Allergens to be used}

While patients are often sensitised to many allergens (polysensitisation), not all of these sensitisations may be clinically relevant. Immunotherapy should target allergens that are most likely responsible for causing the allergic symptoms. Single-allergen extracts (e.g. HDM only) are effective in polysensitised patients (i.e. sensitised to multiple allergen classes apart from HDM). ${ }^{41,42}$

In Singapore, the predominant allergen class is the house dust mite. ${ }^{12}$ The 3 main species are Dermatophagoides pteronyssinus, Dermatophagoides farinae and Blomia tropicalis. ${ }^{17}$ Allergen immunotherapy has been extensively studied and demonstrated to be effective in multiple randomised controlled trials for D. pteronyssinus and D. farinae, ${ }^{43}$ whereas only small-scale studies reported clinical response to AIT with Dermatophagoides extracts in patients who are co-sensitised to both Dermatophagoides and $B$. tropicalis. ${ }^{44,45}$ It is uncertain if polysensitised patients with predominantly $B$. tropicalis reactivity may benefit from AIT, and no recommendation can be made about patients monosensitised to this mite.

Two formulations of SLIT are available in Singapore, and both forms target HDM allergy. The liquid formulation of SLIT has been around for longer, with products from various companies that include $D$. pteronyssinus, D. farinae and B. tropicalis extracts. One other SLIT product comes in tablet form containing D. pteronyssinus and D. farinae extracts and is currently the only tablet form of HDM SLIT in the market. Both formulations of SLIT are administered on a once-daily basis for a recommended treatment course of $3-5$ years. 
- $\quad$ Oral or intranasal $\mathrm{H}_{1}$-antihistamines are less effective than intranasal steroids (INSs) for the control of all rhinitis symptoms. ${ }^{35}$ They are however effective in many patients with mild/ moderate disease and many patients prefer oral medications to intranasal ones.

- $\quad$ Comparisons between oral and intranasal $\mathrm{H}_{1}$ antihistamines differ between recommendations and definite conclusions have not been reached.

- In patients with severe rhinitis, INSs represent the first-line treatment. However, they need a few days to be fully effective.

- The combination of an oral $\mathrm{H}_{1}$-antihistamine and an INS does not offer a better efficacy than INS alone ${ }^{1,36}$ although this practice is common globally.

- $\quad$ MPAzeFlu, the combined intranasal Fluticasone Propionate and Azelastine (Aze) in a single device, is more effective than monotherapy and indicated when monotherapy with INS is considered inadequate, ${ }^{37,38}$ for those with severe AR or for patients who want a rapid symptom relief. ${ }^{1,36}$

- $\quad$ All recommended medications are considered to be safe at the usual dosage. First-generation oral $\mathrm{H}_{1}$-antihistamines are sedating and should be avoided ${ }^{39}$ as well as prolonged use of nasal vasoconstrictors.

- Intramuscular depot corticosteroids are contraindicated for AR.

Fig. 5. Recommendations for pharmacotherapy in allergic rhinitis (AR $)^{32}$

1. Brozek JL, Bousquet J, Agache I, et al. Allergic rhinitis and its impact on Asthma (ARIA) guidelines_-2016 revision. J Allergy Clin Immunol 2017;140:950-8.

32. Bousquet J, Schunemann HJ, Togias A, et al. Next-generation Allergic Rhinitis and Its Impact on Asthma (ARIA) guidelines for allergic rhinitis based on Grading of Recommendations Assessment, Development and Evaluation (GRADE) and real-world evidence. J Allergy Clin Immunol 2020;145:70-80.e3.

36. Dykewicz MS, Wallace DV, Baroody F, et al. Treatment of seasonal allergic rhinitis: an evidence-based focused 2017 guideline update. Ann Allergy Asthma Immunol 2017;119:489-511.e41.

37. Hampel FC, Ratner PH, Van Bavel J, et al. Double-blind, placebo-controlled study of azelastine and fluticasone in a single nasal spray delivery device. Ann Allergy Asthma Immunol 2010;105:168-73.

38. Carr W, Bernstein J, Lieberman P, et al. A novel intranasal therapy of azelastine with fluticasone for the treatment of allergic rhinitis. J Allergy Clin Immunol 2012;129:1282-9.e10.

39. Church MK, Maurer M, Simons FE, et al. Risk of first-generation $\mathrm{H}_{1}$ antihistamines: a GA²LEN position paper. Allergy 2010;65:459-66.
Safety

Allergen drops or tablets are generally very safe. Sublingual immunotherapy can be administered at home after the first dose administered under the supervision of a physician. The majority of adverse events are local reactions (mouth itching, lip swelling and nausea) and spontaneously subside after the first few days of administration. Systemic reactions are fortunately rare and thus far non-fatal. ${ }^{46}$

\section{Practical approach to AIT in the healthcare system}

Allergen immunotherapy is a relatively costly and lengthy treatment. It should be prescribed by a specialist with the patient playing a central role in shared decisionmaking. Appropriate selection of patients, adequate counselling and close follow-up are essential to the success of treatment, as adherence is crucial for efficacy. ${ }^{47}$ GPs should be aware of this modality of treatment and understand the indications for specialist referral.

The 2019 ARIA care pathways recommend a precision medicine approach in selecting an AIT regimen (Fig. 6). ${ }^{48}$

\section{Unmet Needs and Future Opportunities for Singapore}

Moving ahead, we must aim to provide more effective and affordable care for AR patients in an efficient multitiered healthcare system (Fig. 7). In this section, we review the unmet research and clinical needs in AR care in Singapore.

\section{Research needs}

In the last 2 decades, the paucity of Singapore studies on AR care hints at the relative lack of interest towards this disease in comparison to our European counterparts. As society and technologies have progressed, we must question whether the care we provide has evolved to meet the changing needs of our patients. High-quality pragmatic observational studies and examination of real-world evidence are required to assess the effectiveness of practical patient care outside of clinical trials. Future studies may answer the following real-world research questions in the local context:

- Has the disease burden of AR in Singapore changed in the recent decades?

- What are physicians' and patients' knowledge and attitudes towards allergic disease, and how have they evolved in this digitally connected era?

- Are physicians and patients adhering to guideline-based management, and what are the barriers to adherence?

- How effective is guideline-based management in the real-world patient population in Singapore?

- What is the role of emerging management options (e.g. allergen immunotherapy)? 


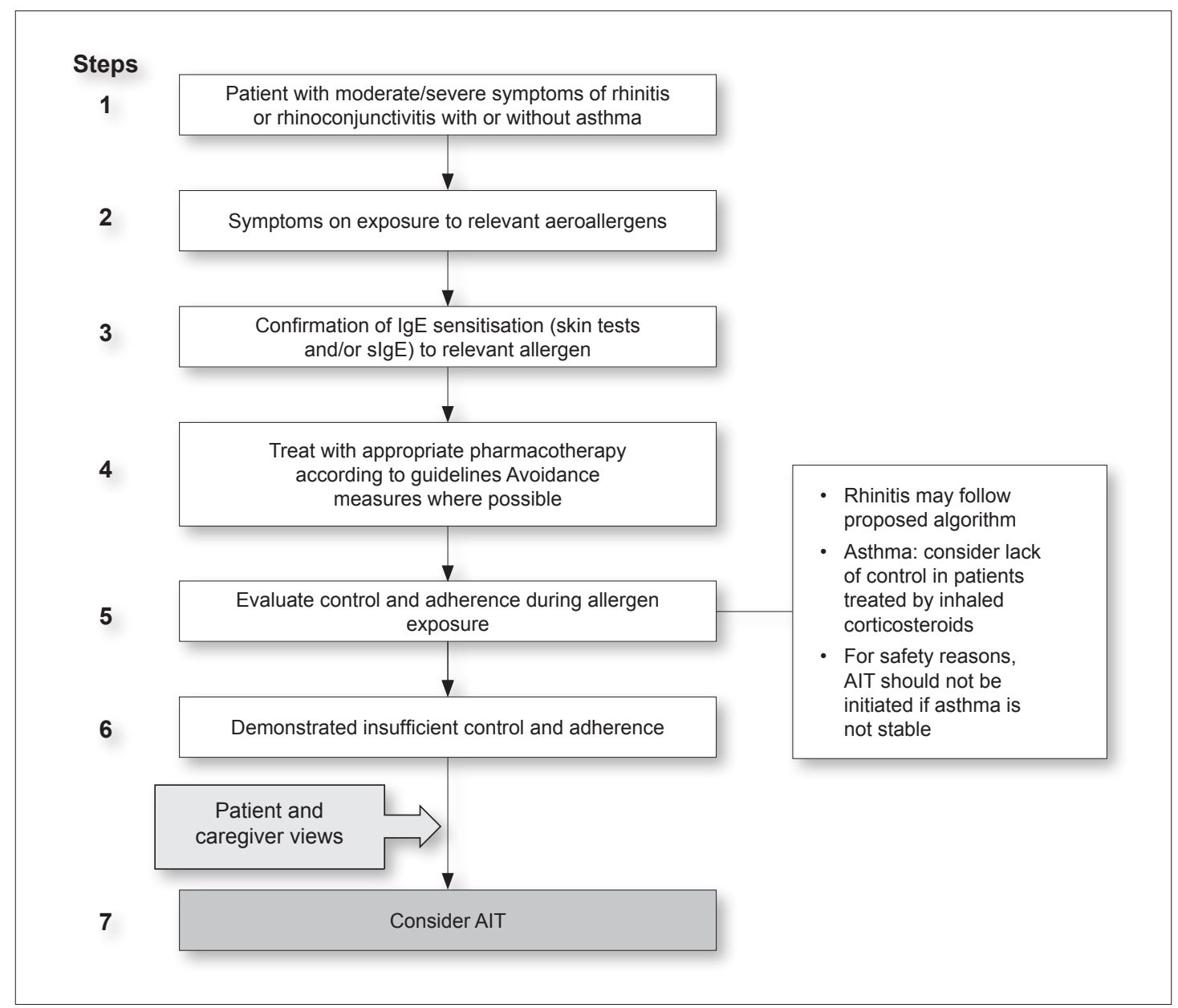

Fig. 6. Flow of precision medicine for allergen immunotherapy (AIT).

Reproduced with permission and adapted from Bousquet J, Khaltaev N, Cruz AA, et al. Allergic Rhinitis and its Impact on Asthma (ARIA) 2008 update (in collaboration with the World Health Organization, GA2LEN and AllerGen). Allergy 2008;63 Suppl 86:8-160; and Canonica GW, Bachert C, Hellings P, et al. Allergen immunotherapy (AIT): a prototype of precision medicine. World Allergy Organ J 2015;8:31

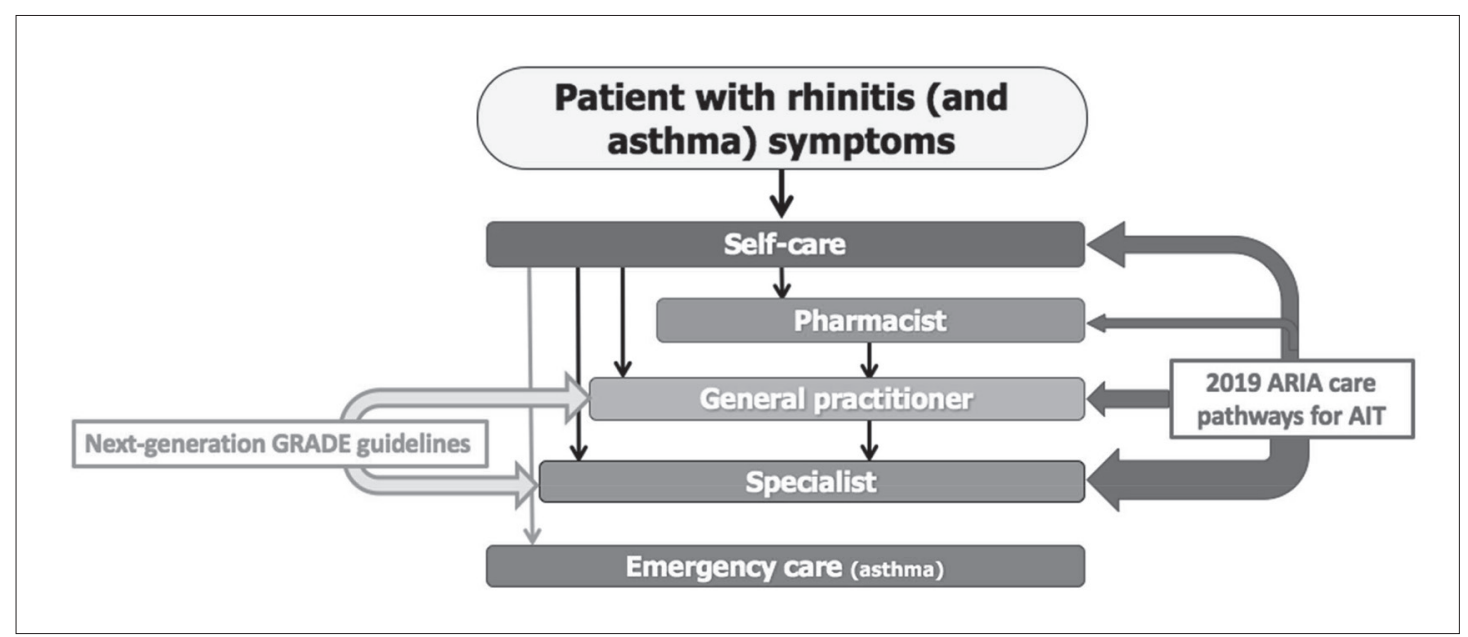

Fig. 7. Summary of next-generation ARIA care pathways considered in the article. Reproduced with permission from Bousquet JJ, Schünemann HJ, Togias A, et al. Next-generation ARIA care pathways for rhinitis and asthma: a model for multimorbid chronic diseases. Clin Transl Allergy 2019;9:44. 
- How cost-effective is our AR care?

- What are patients' attitudes towards mHealth and is its implementation in Singapore feasible?

\section{Clinical needs}

The ongoing aim of ARIA is to establish integrated care pathways that promote the translation of guideline recommendations into local protocols, which include the views of patients and other healthcare providers (Fig. 7).

GPs play a tremendous part in the management of AR, and this role is expected to grow in terms of infrastructure and manpower. By 2030, the total number of governmentsubsidised polyclinics will increase from 24 to $30-32 . .^{50}$ As the first line of outpatient medical care, GPs are pivotal in getting patients access to adequate treatment. Efforts should be concentrated on aligning the primary care sector with guideline recommendations. Ideally, the GP should be able to provide individualised care, identify nuances in the patient's healthcare needs, and troubleshoot therapy adherence over a period of follow-up. When available medical therapy fails to provide adequate control of symptoms, referrals to a specialist can be made for further assessment and for consideration of immunotherapy. It should be noted that $\mathrm{AR}$ is primarily managed medically, although surgery may be a useful adjunct for refractory nasal obstruction and coexistent chronic rhinosinusitis. ${ }^{18}$ Specialists and GPs are close partners in a continuum of medical care who should support a seamless and bidirectional handover of patients. In the multitiered healthcare system, establishing a robust and barrier-free vertical integration between GPs and specialists enhances safety, efficiency and patient satisfaction. There is also a need for the medical fraternity to engage the government and workforce better to address the under-recognised socio-economic burden of undertreated AR on work productivity. More can be done to look into increased government subsidies for AR medications to increase accessibility to the general population.

Pharmacists play an important supporting role. A significant proportion of patients have undiagnosed AR and are self-managed in the community with either overthe-counter drugs or unproven therapies, ${ }^{18}$ which largely produce suboptimal results. A community pharmacist-led AR management initiative has attempted to bridge the gap between self-management and physician-led management. ${ }^{51}$ Where doctors are unable to address patients' issues with compliance, understanding of disease and therapy due to time constraints, there are opportunities for pharmacists to educate and intervene.
For patients who self-manage in the community setting, pharmacists may triage patients to consult GPs and specialists, and potentially identify and educate patients regarding AIT.

Finally, patients themselves are becoming increasingly technology-savvy, information-literate, and more attuned to their personal health. Allergy self-care may begin with health education in primary schools. There is also a broader need for accurate and readily accessible information on allergy care in Singapore via the media and credible online sources. Mobile technology can potentially be harnessed to improve education and empower self-management of the patients' condition. National clinical guidelines may include a patient information section to enhance public awareness.

\section{Conclusion}

Allergic rhinitis is prevalent in Singapore with a significant disease burden. The few local studies from the last 2 decades suggest that there is much room for improvement in the appropriateness of care. Recent efforts of ARIA in Europe have been directed towards empowering patients for self-management, mHealth, and healthcare system-based integrated care pathways. Singapore has the potential to be a model country in allergy care in our modern, highly literate, digitally enabled and interconnected society.

\section{REFERENCES}

1. Brozek JL, Bousquet J, Agache I, et al. Allergic rhinitis and its impact on Asthma (ARIA) guidelines - 2016 revision. J Allergy Clin Immunol 2017;140:950-8.

2. Katelaris $\mathrm{CH}$, Lai $\mathrm{CKW}$, Rhee $\mathrm{CS}$, et al. Nasal allergies in the Asian-Pacific population: results from the Allergies in Asia-Pacific Survey. Am J Rhinol Allergy 2011;25:3-15.

3. Meltzer EO. Allergic rhinitis: burden of illness, quality of life, comorbidities, and control. Immunol Allergy Clin North Am 2016;36:235-48.

4. Vandenplas O, Vinnikov D, Blanc PD, et al. Impact of rhinitis on work productivity: a systematic review. J Allergy Clin Immunol Pract 2018;6:1274-86.e9.

5. Leynaert B, Bousquet J, Neukirch C, et al. Perennial rhinitis: an independent risk factor for asthma in nonatopic subjects: results from the European Community Respiratory Health Survey. J Allergy Clin Immunol 1999;104:301-4.

6. Kulthanan K, Chusakul S, Recto MT, et al. Economic burden of the inadequate management of allergic rhinitis and urticaria in Asian countries based on the GA ${ }^{2} L E N$ model. Allergy Asthma Immunol Res 2018;10:370-8.

7. Bousquet J, Van Cauwenberge P, Khaltaev N. Allergic rhinitis and its impact on asthma. J Allergy Clin Immunol 2001; 108(5 Suppl):S147-334. 
8. Siow JK, Alshaikh NA, Balakrishnan A, et al. Ministry of Health clinical practice guidelines: management of rhinosinusitis and allergic rhinitis. Singapore Med J 2010;51:190-7.

9. Ministry of Health, Singapore. Clinical Practice Guidelines (Medical). 2019. Available at: https://www.moh.gov.sg/hpp/allhealthcare-professionals/guidelines/GuidelineDetails/clinical-practiceguidelines-medical\#withdrawn. Accessed on 3 November 2019.

10. Wang DY, Niti M, Smith JD, et al. Rhinitis: do diagnostic criteria affect the prevalence and treatment? Allergy 2002;57:150-4.

11. Ng TP, Tan WC. Epidemiology of chronic (perennial) rhinitis in Singapore: prevalence estimates, demographic variation and clinical allergic presentation. Ann Acad Med Singap 1994;23:83-8.

12. Andiappan AK, Puan KJ, Lee B, et al. Allergic airway diseases in a tropical urban environment are driven by dominant mono-specific sensitization against house dust mites. Allergy 2014;69:501-9.

13. Emmanuel SC. Impact to lung health of haze from forest fires: the Singapore experience. Respirology 2000;5:175-82.

14. Ministry of Health, Singapore. Healthcare Manpower. Available at: https://www.moh.gov.sg/resources-statistics/singapore-healthfacts/health-manpower. Published 20 April 2018. Accessed on 27 October 2019.

15. Wang DY. Management of allergic rhinitis in general practitioners. Asia Pac Allergy 2012;2:233-6.

16. Loh CY, Chao SS, Chan YH, et al. A clinical survey on compliance in the treatment of rhinitis using nasal steroids. Allergy 2004;59: $1168-72$.

17. Lim MY, Leong JL. Allergic rhinitis: evidence-based practice. Singapore Med J 2010;51:542-50.

18. Bousquet J, Khaltaev N, Cruz AA, et al. Allergic Rhinitis and its Impact on Asthma (ARIA) 2008 update (in collaboration with the World Health Organization, GA(2)LEN and AllerGen). Allergy 2008;63(Suppl 86):8-160.

19. Ministry of Health, Singapore. Drug subsidies and schemes. Available at: https://www.moh.gov.sg/cost-financing/healthcare-schemessubsidies/drug-subsidies-schemes. Accessed on 3 February 2020.

20. Tan NC, Tay IH, Ngoh A, et al. Factors influencing family physicians' drug prescribing behaviour in asthma management in primary care. Singapore Med J 2009;50:312-9.

21. Government of Singapore. Health Products Act, revised edition 2008. Available at: https://sso.agc.gov.sg/Act/HPA2007. Accessed on 3 January 2020.

22. Health Sciences Authority, Singapore. Import and supply of unregistered therapeutic products for patient's use. Available at: https://www.hsa.gov.sg/therapeutic-products/register/special-accessroutes/import-for-patients. Updated 15 January 2020. Accessed on 15 January 2020.

23. Bousquet J, Hellings PW, Agache I, et al. Allergic rhinitis and its impact on Asthma (ARIA) Phase 4 (2018): change management in allergic rhinitis and asthma multimorbidity using mobile technology. J Allergy Clin Immunol 2019;143:864-79.

24. Price D, Smith P, Hellings P, et al. Current controversies and challenges in allergic rhinitis management. Expert Rev Clin Immunol 2015;11:1205-17.

25. Sherman RE, Anderson SA, Dal Pan GJ, et al. Real-world evidence what is it and what can it tell us? N Engl J Med 2016;375:2293-7.

26. Bousquet J, Arnavielhe S, Bedbrook A, et al. MASK 2017: ARIA digitally-enabled, integrated, person-centred care for rhinitis and asthma multimorbidity using real-world-evidence. Clin Transl Allergy 2018;8:45.
27. Bousquet J, Hellings PW, Agache I, et al. ARIA 2016: care pathways implementing emerging technologies for predictive medicine in rhinitis and asthma across the life cycle. Clin Transl Allergy 2016;6:47.

28. Bousquet J, Bedbrook A, Czarlewski W, et al. Guidance to 2018 good practice: ARIA digitally-enabled, integrated, person-centred care for rhinitis and asthma. Clin Transl Allergy 2019;9:16.

29. Bousquet J, Ansotegui IJ, Anto JM, et al. Mobile technology in allergic rhinitis: evolution in management or revolution in health and care? J Allergy Clin Immunol Pract 2019;7:2511-23.

30. Hossain I, Lim ZZ, Ng JJL, et al. Public attitudes towards mobile health in Singapore: a cross-sectional study. Mhealth 2018;4:41.

31. Bousquet J, Anto JM, Annesi-Maesano I, et al. POLLAR: Impact of air POLLution on Asthma and Rhinitis; a European Institute of Innovation and Technology Health (EIT Health) project. Clin Transl Allergy 2018;8:36.

32. Bousquet J, Schunemann HJ, Togias A, et al. Next-generation Allergic Rhinitis and Its Impact on Asthma (ARIA) guidelines for allergic rhinitis based on Grading of Recommendations Assessment, Development and Evaluation (GRADE) and real-world evidence. J Allergy Clin Immunol 2020;145:70-80.e3.

33. Bousquet J, Schunemann HJ, Hellings PW, et al. MACVIA clinical decision algorithm in adolescents and adults with allergic rhinitis. J Allergy Clin Immunol 2016;138:367-74e2.

34. Klimek L, Bergmann KC, Biedermann T, et al. Visual analogue scales (VAS): measuring instruments for the documentation of symptoms and therapy monitoring in cases of allergic rhinitis in everyday health care. Position Paper of the German Society of Allergology (AeDA) and the German Society of Allergy and Clinical Immunology (DGAKI), ENT Section, in collaboration with the working group on Clinical Immunology, Allergology and Environmental Medicine of the German Society of Otorhinolaryngology, Head and Neck Surgery (DGHNOKHC). Allergo J Int 2017;26:16-24.

35. Brozek JL, Bousquet J, Baena-Cagnani CE, et al. Allergic Rhinitis and its Impact on Asthma (ARIA) guidelines: 2010 revision. J Allergy Clin Immunol 2010;126:466-76

36. Dykewicz MS, Wallace DV, Baroody F, et al. Treatment of seasonal allergic rhinitis: an evidence-based focused 2017 guideline update. Ann Allergy Asthma Immunol 2017;119:489-511.e41.

37. Hampel FC, Ratner PH, Van Bavel J, et al. Double-blind, placebocontrolled study of azelastine and fluticasone in a single nasal spray delivery device. Ann Allergy Asthma Immunol 2010; 105:168-73.

38. Carr W, Bernstein J, Lieberman P, et al. A novel intranasal therapy of azelastine with fluticasone for the treatment of allergic rhinitis. J Allergy Clin Immunol 2012;129:1282-9.e10.

39. Church MK, Maurer M, Simons FE, et al. Risk of first-generation $\mathrm{H}_{1}$-antihistamines: a GA ${ }^{2} \mathrm{LEN}$ position paper. Allergy 2010; 65:459-66.

40. Muraro A, Roberts G, Halken S, et al. EAACI guidelines on allergen immunotherapy: executive statement. Allergy 2018;73:739-43.

41. Liu X, Ng CL, Wang Y. The efficacy of sublingual immunotherapy for allergic diseases in Asia. Allergol Int 2018;67:309-19.

42. Nelson H, Blaiss $M$, Nolte $H$, et al. Efficacy and safety of the SQ-standardized grass allergy immunotherapy tablet in monoand polysensitized subjects. Allergy 2013;68:252-5.

43. Radulovic S, Calderon MA, Wilson D, et al. Sublingual immunotherapy for allergic rhinitis. Cochrane Database of Syst Rev 2010;(12):CD002893. 
44. Soh JY, Thalayasingam M, Ong S, et al. Sublingual immunotherapy in patients with house dust mite allergic rhinitis: prospective study of clinical outcomes over a two-year period. J Laryngol Otol 2016;130:272-7.

45. Chen S, Zheng Y, Chen B, et al. Clinical response to subcutaneous Dermatophagoides pteronyssinus immunotherapy in children with allergic rhinitis and asthma is independent of sensitization to Blomia tropicalis allergens. Int Arch Allergy Immunol 2019;178:201-10.

46. James C, Bernstein DI. Allergen immunotherapy: an updated review of safety. Curr Opin Allergy Clin Immunol 2017;17:55-9.

47. Nam YH, Lee SK. Physician's recommendation and explanation is important in the initiation and maintenance of allergen immunotherapy. Patient Prefer Adherence 2017;11:381-7.
48. Canonica GW, Bachert C, Hellings P, et al. Allergen immunotherapy (AIT): a prototype of precision medicine. World Allergy Organ J 2015;8:31

49. Bousquet JJ, Schünemann HJ, Togias A, et al. Next-generation ARIA care pathways for rhinitis and asthma: a model for multimorbid chronic diseases. Clin Transl Allergy 2019;9:44.

50. Baker JA. MOH to build up to 8 new polyclinics by 2030 . Channel News Asia. 7 March 2018. Available at: https://www. channelnewsasia.com/news/singapore/moh-to-build-up-to-8-newpolyclinics-by-2030-10022706. Accessed on 27 October 2019.

51. Yap JSY, Tang CWQ, Hor HML, et al. Process evaluation of the Community Pharmacist-Led Allergic Rhinitis Management (C-PhARM) service in Singapore. Pharmacy (Basel) 2019;7:56. 